\title{
Temporal evolution of physical and dielectric properties of sea ice and snow during the early melt season: observations from SIMS '90 experiment
}

\author{
MOHAMMEd E. SHOKR \\ Atmospheric Environment Service, North York, Ontario M3H 5T4, Canada \\ DAVID G. BARBER \\ Earth Observation Laboratory, Institute for Space and Terrestrial Science, University of Waterloo, Waterloo, \\ Ontario N2L 3G1, Canada
}

\begin{abstract}
The first field experiment in the 5 year seasonal Sea Ice Monitoring Site (SIMS) program was conducted in Resolute Passage, Canadian Eastern Arctic, between 15 May and 8 June 1990. This period signals the early melt season of sea ice in that region. A standard array of ice and snow measurements was collected on a daily basis from first-year and multi-year ice to monitor temporal evolution. Measurements included ice salinity, ice temperature and ice-surface roughness, snow salinity, snow temperature, snow density and snow depth. The complex dielectric constant of sea ice was computed from these measurements. Rapid desalination of first-year ice was noticed in the surface layer. Towards the end of the experiment period, salinities of the snow-hoar layer were higher than those of the ice-surface layer. Variation in air temperature is replicated by ice-surface temperature but not by the salinity or dielectric properties. No temporal variation in permittivity and dielectric loss was observed for first-year ice, but a slight increase in both parameters was observed for multi-year ice. As a result, a slight decrease in the microwavepenetration depth was observed for multi-year ice. Physical properties of ice and snow were compared against results obtained from other experiments conducted in different ice-formation regions in the late winter and in the early melt season.
\end{abstract}

\section{INTRODUGTION}

Sea-ice and snow-cover properties change throughout the annual seasonal cycle. Monitoring of these changes is required to understand the geophysical processes operating through the ocean-ice-atmosphere interface. Sea-ice seasonal evolution is defined within the context of microwave scattering into five seasons: winter, early melt, melt onset, advanced melt and freeze-up (Livingstone and others, 1987b). This seasonal ordination is contingent upon the sea-ice conditions, and micro- and macro-climatology of the region. The most dynamic seasons, from the perspective of energy, mass, momentum and microwave-scattering principles, are early melt and the melt onset. The first is the subject of this study.

Early melt is a transition period starting with the beginning of snowpack metamorphism and ending when moisture is continuously present in the snow. Metamorphic processes are affected by kinetic energy (windinduced metamorphosis) and radiant energy. Radiant energy provides for development of ice lenses and ice layers within the snowpack (Miller, 1981). Kinetic processes cause metamorphosis from a faceted hexagonal snowflake with inter-crystal pore spaces consisting primarily of air to a more-rounded grain state (Colbeck,
1982). This can cause density changes from light newly fallen snow $\left(\sim 0.05 \mathrm{Mg} \mathrm{m}^{-3}\right)$ to very dense crustal snow layers $\left(\sim 0.5 \mathrm{Mg} \mathrm{m}^{-3}\right)$. Air temperatures at the surface rise to $0^{\circ} \mathrm{C}$ during some part of the day and diurnal temperature variations (melt-freeze cycles) occur. If ambient conditions return to winter norms, these changes can be retained within the snow structure, thereby creating a thermal history within the snow volume. Desalination of the ice surface progresses at a rate greater than that of the winter period (Holt and Digby, 1985). This promotes changes in brine volume, which affect ice-dielectric properties, microwave scattering, thermo-dynamic and mechanical properties.

Dielectric properties and microwave scattering from a seasonally dynamic snow-covered sea-ice volume are poorly understood, primarily because of the lack of quantitative surface data coincident with the seasonal evolution (Livingstone and others, 1987a). The problem is compounded by the spatial and temporal uniqueness within which these seasonal changes occur. Characteristics of the geophysical properties of snow and sea ice, through early melt and melt onset can vary regionally and inter-annually. Ice-characterization studies have shown that different ice types and ice-surface and volume conditions are encountered in different regions. Surface 
conditions of first-year ice, for example, depend on regional atmospheric, thermal, tidal and other compressional forces. Ice-volume properties and structure are mainly influenced by the growth rate of the ice cover which, again, varies according to regional environmental conditions.

In order to address the seasonal and inter-annual variation of sea-ice properties, an experimental program involving coordinated surface-validation measurements and synthetic-aperture radar (SAR) overflights was undertaken through the seasonal Sea Ice Monitoring Site (SIMS) program. The first experiment in this program was conducted in the Barrow Strait/Lancaster Sound region of the Canadian Arctic Archipelago, during the period 15 May-8 June 1990. Durings SIMS '90, the physical state of the atmospheric boundary layer, snow and sea-ice physical properties can best be summarized as the "early melt season". In order to address the heterogeneity ascribed to regional scale differences, results from six experiments conducted during late winter and early melt seasons in different regions are compared to the SIMS '90 results. This type of comparison is required because of the near-future era of global coverage of sea ice with space-borne SAR, and of the scientific requirements for separation of environmental variability from that of natural change.

The objectives of this study are: (1) to characterize the spatial and temporal variability in the geophysical properties which give rise to the dielectric and microwave-scattering properties of snow and ice; (2) to compare observations from SIMS ' 90 to those collected in similar seasonal but different regional and inter-annual conditions. By addressing these objectives, we hope to illuminate the range and magnitude of physical and electrical properties of the sea ice.

\section{METHODS}

\subsection{The SIMS '90 field experiment}

The SIMS '90 field experiment was the first in a series of experiments. The overall purpose of the program is to study geophysical processes of air/snow/ice interaction within describable boundaries arising from intra- and inter-annual changes of geophysical properties within a homogeneous region. The general scope of the program has been presented by Barber (1990).

\subsubsection{Site location}

The SIMS '90 field-sampling program consisted of $23 \mathrm{~d}$ of data collection from 15 May to 8 June 1990. Field operations were based at the Polar Continental Shelf Project (PCSP) in Resolute Bay, Northwest Territories (Fig. 1). Ice and snow data were sampled from two areas, designated as intensive and extensive (Fig. 1). Within the intensive sampling area, four sampling sites were selected after an initial reconnaissance of the fast-ice conditions in Resolute Passage. Each site was identified using visual flagging and was visited daily on a rotating basis throughout the experiment. The four sites were designated (Fig. 2): Home (early consolidated, smooth firstyear ice), FYI (late consolidated first-year ice), MYI

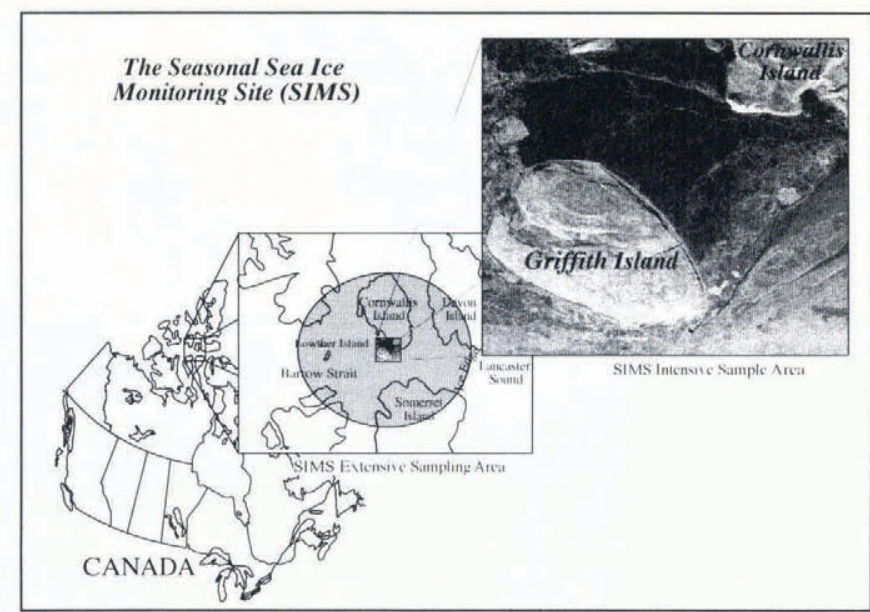

Fig. 1. Geographic site of the SIMS'90 experiment.

(multi-year ice) and TRANSECT (12.5 km long transit across Resolute Passage). At each of the sites, FYI, Home and MYI, a $100 \mathrm{~m} \times 50 \mathrm{~m}$ sample grid was used to collect the physical property measurements.

The Home site consisted of smooth first-year ice. The ice at this site consolidated in late September 1989, according to information obtained from Ice Charts produced by the Canadian Atmospheric Environment Service. The FYI site was located approximately $6 \mathrm{~km}$ to the southeast of Sight Point near Resolute Bay. Consolidation time for the FYI site is estimated at late December or early January. The MYI site was located approximately $6 \mathrm{~km}$ to the southwest of the FYI site in the middle of a $2 \mathrm{~km}$ diameter multi-year floe situated at the edge of a first-year rubble zone (Fig. 2). The transect site was established as a traverse across Resolute Passage from a distinguishable V-notch valley on Griffith Island across to Cape Martyr on Cornwallis Island. The ice in this part of Resolute Passage consolidated in late October 1989. Ten sites spaced $1 \mathrm{~km}$ apart were sampled across the transect starting from $1 \mathrm{~km}$ off the shore of Griffith Island. The tenth site was located approximately $2.5 \mathrm{~km}$ from the Cape Martyr shore (Fig. 2). Details of site selection and specific ice and snow characteristics have been described elsewhere (Flett and others, 1990; Barber and others, 1991).

\subsubsection{Geophysical variables}

Most of the data on snow and ice properties were collected during "snow-pit sampling". This involved excavating ten snow pits, oriented along the long axis of the sampling site (i.e. $100 \mathrm{~m}$ dimension). The snow measurements used in this study were temperature, depth, salinity and density. The ice measurements were temperature, salinity and surface roughness.

\subsubsection{Snow variables}

Snow-temperature profiles included temperature measurements of air, air/snow interface, snowpack and ice temperature $(\sim 2.5 \mathrm{~cm}$ into the ice). Temperatures were measured using thermocouple probes with digital readout to a Fluke temperature meter accurate to $0.1^{\circ} \mathrm{C}$. Snowpack temperatures were collected by inserting the probe $5-10 \mathrm{~cm}$ into the snow along an undisturbed, 


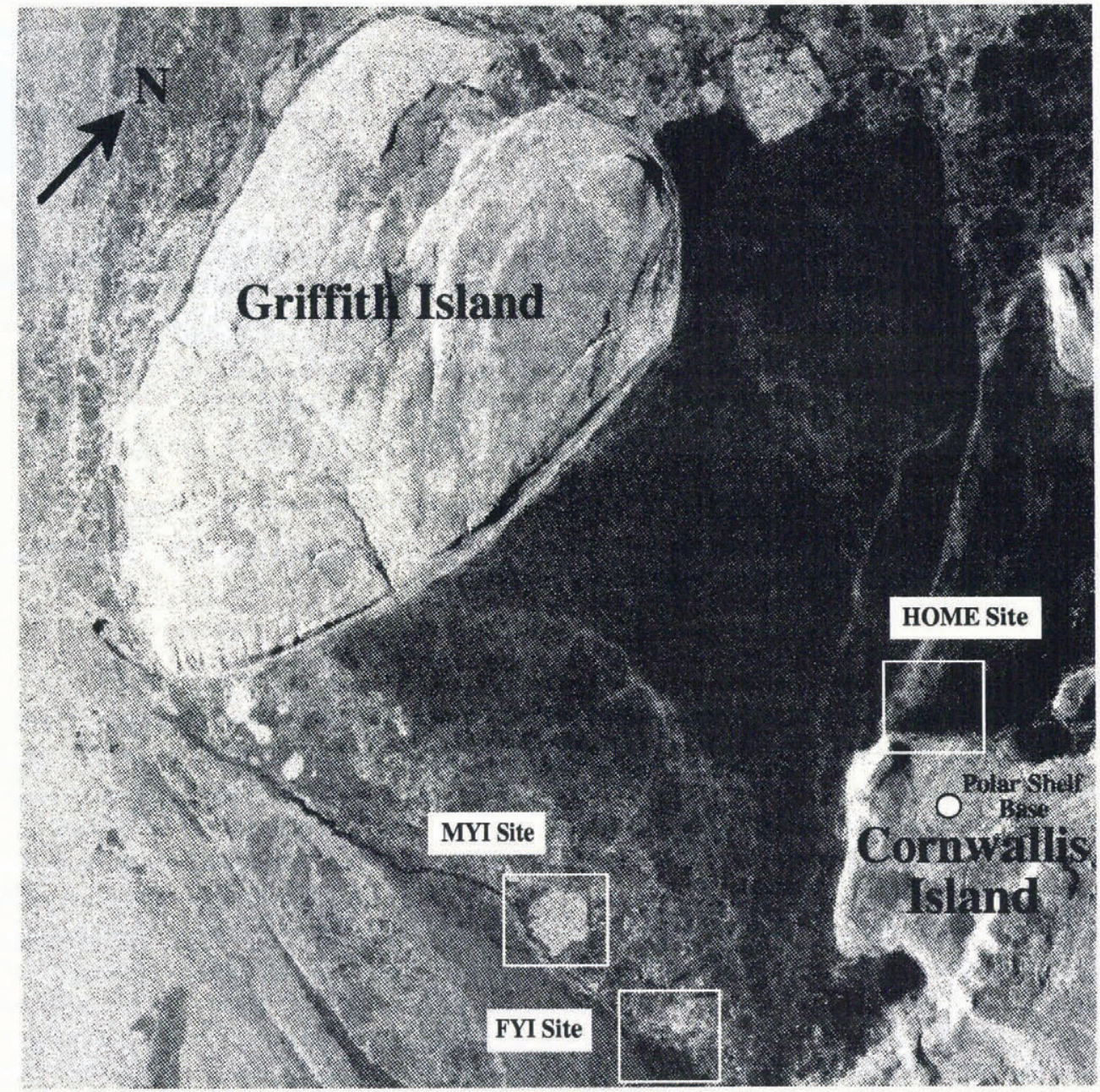

Fig. 2. STAR-2 SAR image of SIMS'90 showing geographic place-names and sampling areas.

diffusely illuminated edge of a snow pit. Temperatures were taken at $5 \mathrm{~cm}$ intervals starting $5 \mathrm{~cm}$ above the ice surface progressing upward. Snow/ice interface temperatures were measured with the probe inserted $5-10 \mathrm{~cm}$ into the snow/hoar layer at the ice surface. Ice temperatures were measured by hand-drilling approximately $2.5 \mathrm{~cm}$ into the ice and inserting the probe until firm contact was made with the sea ice.

Snow depths and hoar depths were measured at each snow pit using a $1 \mathrm{~m}$ stick. Samples of depth hoar (if present) and surface snow were collected and analyzed for salinity using a hand-held Atago optical salinometer accurate to $\pm 0.1 \mathrm{ppt}$. Snow density was measured using a standard volume from the top snow layer and weighing the sample. The error estimate on this method is approximately $\pm 0.03 \mathrm{Mg} \mathrm{m}^{-3}$ (Garrity and Burns, 1988). Snow grain-size was visually estimated to the nearest $\mathrm{mm}$ using gridded graph paper. A small number of snow-wetness measurements was made with a field resometer (Garrity, 1990).

\subsubsection{Ice variables}

Temperature- and salinity-profile measurements were obtained from vertical ice cores. Cores were extracted using a gas-powered coring auger. Cores were drilled and analyzed immediately after they were extracted to preserve their temperature and salinity. Temperature profiles were obtained by chipping or drilling a hole into the core through which a thermocouple probe was inserted. Salinity samples were taken starting at the top (ice surface) and progressing downward at $10 \mathrm{~cm}$ intervals to the bottom of the core. Salinity samples were also obtained from the top $5 \mathrm{~mm}$ of the ice surface at snow-pit locations. All samples were analyzed at the PCSP base using the Atago salinometer.

Ice depth and free-board were recorded periodically by drilling holes with a gas-powered auger $(10 \mathrm{~cm}$ diameter and $6 \mathrm{~m}$ of drill flights) and using weighted measuring tapes. Ice-surface micro-scale roughness was measured using a prototype instrument called a surfaceroughness meter (SRM). Micro-scale roughness is defined as the $\mathrm{mm}$ to $\mathrm{cm}$ scale changes in the vertical and horizontal roughness of the surface. The two surfaceroughness parameters obtained are r.m.s. height $\left(\sigma_{\mathrm{h}}\right)$ and correlation length $(L)$. The instrument illuminates a rectangle of known dimension on to the surface. This illuminated area is then photographed. The photographs are digitized into a microcomputer and point estimates of $\sigma_{\mathrm{h}}$ and $L$ are obtained from specialized analysis software (Paterson, 1990).

\subsection{Regional sea-ice experiments}

Results from six previous experiments (Table 1) conducted during late winter and early melt are used to address the heterogeneity ascribed to regional-scale 


\section{Experiment Geographic area Lat.-Long. Month(s) rear Reference}

\begin{tabular}{|c|c|c|c|c|c|}
\hline $\begin{array}{l}\text { AIDJEX } \\
\text { OCSEAP }\end{array}$ & $\begin{array}{l}\text { Beaufort Sea } \\
\text { Beaufort Sea, } \\
\text { North of Alaska }\end{array}$ & $75^{\circ} \mathrm{N}, 148^{\circ} \mathrm{W}$ & $\begin{array}{l}\text { Mar-Apr } \\
\text { Jan-May }\end{array}$ & $\begin{array}{l}1972 \\
1976\end{array}$ & $\begin{array}{l}\text { Cox and Weeks, } 1974 \\
\text { Martin, } 1979\end{array}$ \\
\hline PNDINLT & $\begin{array}{l}\text { Pond Inlet, } \\
\text { Baffin Island }\end{array}$ & $72^{\circ} \mathrm{N}, 78^{\circ} \mathrm{W}$ & Nov-Jul & $\begin{array}{l}1977 \\
1978\end{array}$ & $\begin{array}{l}\text { Nakawo and Sinha, } \\
1981\end{array}$ \\
\hline MLDBAY & $\begin{array}{l}\text { Mould Bay, } \\
\text { Arctic Archipelago }\end{array}$ & $76^{\circ} \mathrm{N}, 119^{\circ} \mathrm{W}$ & Jun-Jul & 1982 & Holt and Digby, 1985 \\
\hline MIZEX'84 & $\begin{array}{l}\text { Fram Strait, } \\
\text { Greenland Sea }\end{array}$ & $\begin{array}{l}79^{\circ} \mathrm{N} \\
-7^{\circ} \text { to }+7^{\circ}\end{array}$ & Jun-Jul & 1984 & Tucker and others, 1987 \\
\hline WWSP'86 & $\begin{array}{l}\text { Weddell Sea, } \\
\text { Antarctica }\end{array}$ & $\begin{array}{l}65^{\circ} \mathrm{S} \\
-5^{\circ} \text { to }+5^{\circ}\end{array}$ & Oct-Dec & 1988 & Eicken and Lange, 1989 \\
\hline
\end{tabular}

differences while attempting to hold constant microscale atmospheric forcing driving the seasonal evolution. The six sites were selected from a review of the current literature on snow and ice physical properties. These regions are considered separate "ice-formation regions" where the magnitude and dynamics of snow and sea-ice geophysical properties will be driven by the regional predominance of atmospheric and hydrospheric forcings on the snow-covered sea-ice volume.

Of the six sites selected (Table 1), five are from the Northern Hemisphere and one from the Southern Hemisphere. The sites were selected not because of the detailed analysis done on the required variables but rather in an attempt to contrast results from SIMS '90 with experimental measurements from other geographic regions. It should be mentioned that a comprehensive comparison between ice and snow properties obtained in different experiments is hindered by the lack of standard sampling methodology and measuring techniques. Therefore, only a brief comparison is conducted in this study. Throughout the rest of this paper, each experimental site will be referred to by the code name specified in column 1 in Table 1. The following acronyms are employed: Arctic Ice Dynamics Joint Experiment (AIDJEX), Outer Continental Shelf Environmental Assessment Program (OCSEAP), Pond Inlet Baffin Bay Experiment (PNDINLT), Mould Bay Experiment (MLDBAY), Marginal Ice Zone Experiment 1984 (MIZEX'84), the Winter Weddell Sea Project 1986 (WWSP'86). The literature reference cited in column 6 should be consulted if no other reference to the pertinent experiment is mentioned.

\subsection{Ice temperature and dielectric models}

A model for ice-surface temperature was examined using the present data. The model was developed by Nakawo and Sinha (1981) based on Stefan's equation (Carslaw and Jaeger, 1959). It relates ice-surface temperature $\left(T_{\mathbf{8}}\right)$ to air temperature $\left(T_{\mathrm{a}}\right)$ for a given snow thickness $\left(d_{8}\right)$ and ice thickness $\left(d_{i}\right)$. The assumption inherent in the model is that the heat flux in both ice and snow is constant and equal. This is usually valid under normal winter steady-state conditions.

$$
T_{\mathrm{s}}=\left(K_{\mathrm{i}} d_{\mathrm{s}} T_{\mathrm{m}}+K_{\mathrm{s}} d_{\mathrm{i}} T_{\mathrm{a}}\right) /\left(K_{\mathrm{i}} d_{\mathrm{s}}+K_{\mathrm{s}} d_{\mathrm{i}}\right)
$$

where $K_{\mathrm{i}}$ and $K_{\mathrm{s}}$ are the thermal conductivities of ice and snow, respectively; and $T_{\mathrm{m}}$ is the freezing point of the sea water $\left(-1.8^{\circ} \mathrm{C}\right)$. The thermal conductivity of ice was selected according to Schwertfeger (1963) to be $5 \times$ $10^{-3} \mathrm{cal}(\mathrm{cmsdeg})^{-1}$. This value is valid for sea ice of about 6 ppt salinity, which is compatible with the present experimental results. The thermal conductivity of snow, according to Mellor (1977), is $6 \times 10^{-4} \mathrm{cal}\left(\mathrm{cm} \mathrm{s} \mathrm{deg}^{-1}\right.$. This value is valid for a snow density of $0.350 \mathrm{Mg} \mathrm{m}^{-3}$ at air temperatures between $-20^{\circ}$ to $-30^{\circ} \mathrm{C}$. Although this temperature range is much lower than the average temperature in the present data, we selected this value because the specified snow density agreed with the present data.

The dielectric property of sea ice and snow that is most important for microwave sacttering is the complex dielectric constant $\epsilon$ (measured in units of Farad m${ }^{-1}$ )

$$
\epsilon=\epsilon^{\prime}-j \epsilon^{\prime \prime} \text {. }
$$

The real part is the permittivity and the imaginary part is the dielectric loss. In terms of dielectric constant, sea ice can be considered as a three-phase medium: pure ice crystals, air inclusions and brine inclusions. Each phase has a different complex dielectric constant at microwave frequencies and exists in different characteristic sizes, shapes and distributions. Since the typical dimensions of inclusions (approximately $1-10 \mathrm{~mm}$ ) are within one-tenth of wavelengths commonly used in sea-ice microwave remote-sensing, the microwave scattering is expected to be influenced by the three-phase combinations (Weeks and Ackley, 1982).

In the case of first-year ice, the permittivity is primarily influenced by brine inclusions. The permittivity of brine is $10-20$ times higher than the typical value of 3.15 for pure ice. Brine volume increases with temperature and so does the permittivity of the ice mixture. The dielectric loss is also temperature-sensitive, since it depends on the phase of the salt components (i.e. the 
solid salt) in the liquid brine. More solid salt is formed as temperature decreases. The dielectric loss increases with temperature in the range $-20^{\circ}$ to $0^{\circ} \mathrm{C}$. It also depends on frequency, since the dielectric properties of water (contained in brine liquid) depend on frequency in the microwave range (Hoekstra and Spanogle, 1972).

For multi-year ice, bulk salinities of the upper surface are low and therefore the permittivity is less than that for first-year ice. Typical values of permittivity are close to those of pure ice (Ulaby and others, 1986). The dielectric loss is also lower than that for first-year ice. Both permittivity and dielectric loss are frequency-independent and much less temperature-sensitive at temperatures below $-10^{\circ} \mathrm{C}$.

Several models have been developed for calculation of the complex dielectric constant of sea ice. Models vary in their degree of complexity, ranging from empirical equations based on experimental data to theoretical models that take into consideration the shape, size, orientation and distribution of inclusions. Two simple models for sea ice were used in this study. The models were applied to profile measurements and to temporal records of ice and snow parameters in order to examine the evolution of the permittivity and loss during the early melt season. The first model (Vant and others, 1978) is based on empirical results from the AIDJEX program. The model uses linear approximations of the permittivity and loss terms as a function of brine-volume fraction $V_{\mathrm{b}}$. For first-year ice, and for a range of microwave frequencies around $4 \mathrm{GHz}$ (which is close to the operational radar C-band $5.3 \mathrm{GHz}$ ), the permittivity and loss are given by the following equations:

$$
\begin{aligned}
\epsilon^{\prime} & =3.05+7.20 V_{\mathrm{b}} \\
\epsilon^{\prime \prime} & =0.024+3.30 V_{\mathrm{b}} .
\end{aligned}
$$

For multi-year ice, and for microwave frequencies around $10 \mathrm{GHz}$ (which is close to the operational radar X-band $9.25 \mathrm{GHz}$ ), the following equations are used:

$$
\begin{aligned}
\epsilon^{\prime} & =2.460+22.0 V_{\mathrm{b}} \\
\epsilon^{\prime \prime} & =0.006+10.0 V_{\mathrm{b}} .
\end{aligned}
$$

The second model is a simplified expression developed by Hoekstra and Cappillino (1971) based on Polder-Van Santen/de Loor dielectric model (Loor, 1968) for a twophase mixture with spherical inclusions. The validity of the model was established for first-year ice. The expressions for the permittivity and loss are as follows:

$$
\begin{aligned}
\epsilon^{\prime} & =3.15 /\left(1-3 V_{\mathrm{b}}\right) \\
\epsilon^{\prime \prime} & =V_{\mathrm{b}} \epsilon_{\mathrm{b}}{ }^{\prime \prime}
\end{aligned}
$$

where $\epsilon_{\mathrm{b}}{ }^{\prime \prime}$ is the dielectric loss of liquid brine. In this study, a constant value of $\epsilon_{\mathrm{b}}{ }^{\prime \prime}=50$ was chosen. This value is valid for ice temperatures around $-5^{\circ} \mathrm{C}$ and for electromagnetic wavelengths in the range $4-10 \mathrm{~cm}$ (Stogryn, 1971). The brine volume (in ppt) in the above equations can be computed from the measured salinity $(S)$ in ppt and ice temperature $(T)$ in ${ }^{\circ} \mathrm{C}$, using an empirical equation developed by Frankenstein and Garner (1967). Validity conditions for this model consist of a temperature range between $-0.5^{\circ}$ and $-22.9^{\circ} \mathrm{C}$ :

$$
V_{\mathrm{b}}=10^{-3} S[-(49.185 / T)+0.532] \text {. }
$$

The ratio between the dielectric constant and loss (called loss tangent) is related to the attenuation of microwave energy in the medium. This ratio is used in calculating the penetration depth $\delta$ (at which the incident energy has been reduced to $1 / e$ ) of an electromagnetic wave into ice, following an equation proposed by Evans (1965):

$$
\delta=\frac{\lambda}{4 \pi}\left\{\frac{\epsilon^{\prime}}{2}\left[\sqrt{1+\left(\frac{\epsilon^{\prime \prime}}{\epsilon^{\prime}}\right)^{2}-1}\right]\right\}^{-\frac{1}{2}}
$$

where $\lambda$ is the incident wavelength.

\section{RESULTS AND DISCUSSION}

\subsection{Measured ice properties}

\subsubsection{Temperature profiles}

Temperature profiles representative of first-year and multi-year ice from the SIMS '90 experiment are shown in Figure $3 a$ and b, respectively. Profiles 1, 2, 3 and 4 in
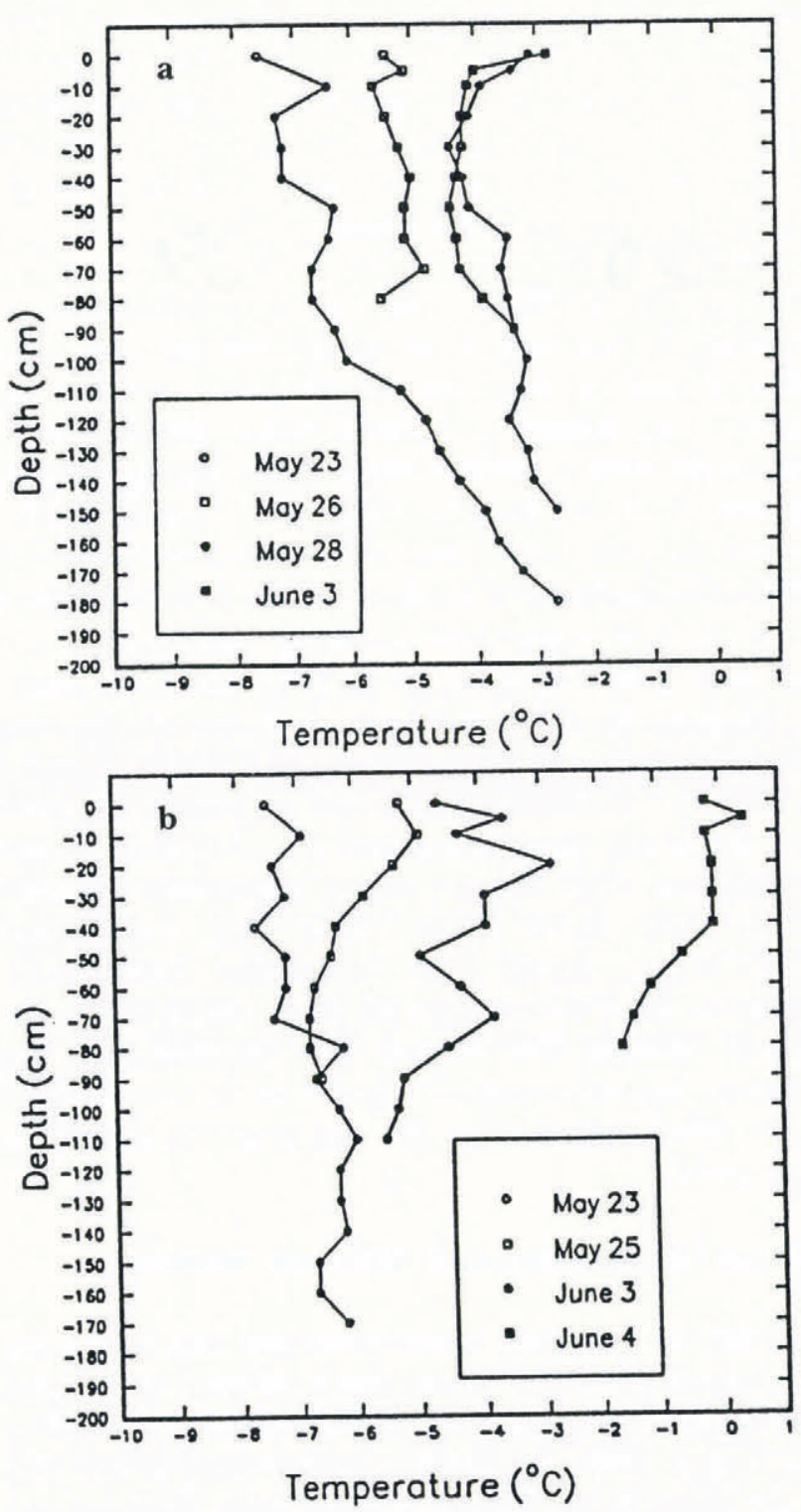

Fig. 3. Temperature profiles measured from cores of $a$, first-year ice and b, multi-year ice. 
Figure 3 a were associated with air temperatures of $-7.6^{\circ}$, $-5.3^{\circ},-2.9^{\circ}$ and $-3.1^{\circ} \mathrm{C}$, respectively, while profiles $1,2,3$ and 4 in Figure $3 \mathrm{~b}$ were associated with air temperatures of $-7.5^{\circ},-5.2^{\circ},-4.6^{\circ}$ and $-0.2^{\circ} \mathrm{C}$. It can be seen in both of these figures that, as the air temperature increases, the warming effect advances gradually through the ice. Profiles 2, 3 and 4 in both figures deviated from the typical pattern usually observed under cold winter conditions, namely, the monotonic linear temperature increase with depth (Nakawo and Sinha, 1981). The deviation is characterized by a negative (or zero) temperature gradient within the $30-80 \mathrm{~cm}$ ice layer, and is followed by the expected positive gradient. This pattern is evident especially in the case of first-year ice, and is evoked at an atmospheric temperature of approximately $-5^{\circ} \mathrm{C}$ (Fig. $3 \mathrm{a}$ and $\mathrm{b}$ ). The thermal history of the atmosphere and the ice-surface layer has an important role in defining the depth at which the sign of the temperature gradient changes.

Temperature profiles observed in the Beaufort Sea (OCSEAP experiment) and in Fram Strait (MIZEX '84 experiment) showed a negative temperature gradient within the upper ice layer. The air temperature in those experiments was near $-2^{\circ} \mathrm{C}$. In the Weddell Sea (WWSP'86) experiment, temperature profiles measured in the early melt season were found to increase linearly with ice depth when the air temperature ranged between $-3^{\circ}$ and $-12^{\circ} \mathrm{C}$. Isothermal profiles were observed when the air temperature was above $-3^{\circ} \mathrm{C}$. The same observation was reported in the PNDINLT experiment, i.e. isothermal profiles were measured in the top $30 \mathrm{~cm}$ layer when air temperatures above $-3^{\circ} \mathrm{C}$ prevailed. In summary, it would appear that an approximately linear temperature gradient within the sea ice can be expected for temperatures below $-5^{\circ} \mathrm{C}$. As the air temperatures rise, there is a tendency for this gradient to become isothermal. Observations at air temperatures at $-3^{\circ} \mathrm{C}$ coincide with the appearance of the isothermal profiles (within the top $30-80 \mathrm{~cm}$ of the sea-ice volume). Seasonal and diurnal effects of air temperature would have approximately similar effects on the temperature gradient of sea ice regardless of geographic differences in ice micro-structure.

\subsubsection{Salinity profiles}

Sea water typically contains $30-35 \mathrm{ppt}$ of sodium chloride. During sea-ice formation and early growth, rapid desalination takes place (Weeks and Ackley, 1982). When ice has reached a thickness of approximately $40 \mathrm{~cm}$, desalination proceeds at a much slower rate. Typical ice salinities are $10-15 \mathrm{ppt}$ for new ice, 5-8 ppt for first-year ice of 1-2 m thickness and $0.1-3$ ppt for multi-year ice (Weeks, 1981). At the beginning of the seasonal transition, the snow cover or sea ice undergoes a process of constructive metamorphosis. This results in the formation of polycrystalline aggregates, snow-crystal enlargement and formation of water, in the liquid phase, within the interstices of the snowpack. The geophysical changes lead to a reduction in the integrated climatological albedo $(\alpha)$ of the snow volume. This reduction in $\alpha$ increases the amount of energy available for snow and sea-ice phase-change processes and in effect operates as a positive feed-back mechanism (i.e. as melt progresses, $\alpha$ drops and more melt is promoted). The phase changes from solid to vapour and liquid within the snow layer promote desalination of the hoar layer and of the ice upper surface both through gravity drainage and through brine-flushing mechanisms.

Salinity profiles from selected cores collected during SIMS '90 are shown in Figure $4 \mathrm{a}$ and b for first-year and multi-year ice types, respectively. Profiles in both figures were obtained from the same cores, from which temperature profiles in Figure $3 \mathrm{a}$ and $\mathbf{b}$ were measured. We note that these profiles are representative of other measured profiles that show the same desalination trend as described in the following. Figure $4 \mathrm{a}$ shows the top layer of the first-year ice starting to loose brine in the last week of May. Profile 1, measured on 23 May demonstrates an average salinity of $13 \mathrm{ppt}$ within the top $10 \mathrm{~cm}$. This value, however, drops to approximately $11,8.5$ and $8.0 \mathrm{ppt}$ in profiles 2, 3 and 4, which were collected on 26 May, 28 May and 3 June, respectively. By relating those profiles to the corresponding temperature profiles in Figure $3 \mathrm{a}$, it can be seen that desalination in the icesurface layer advances within a short period of time (a day or two) following an air-temperature rise above $-5^{\circ} \mathrm{C}$.
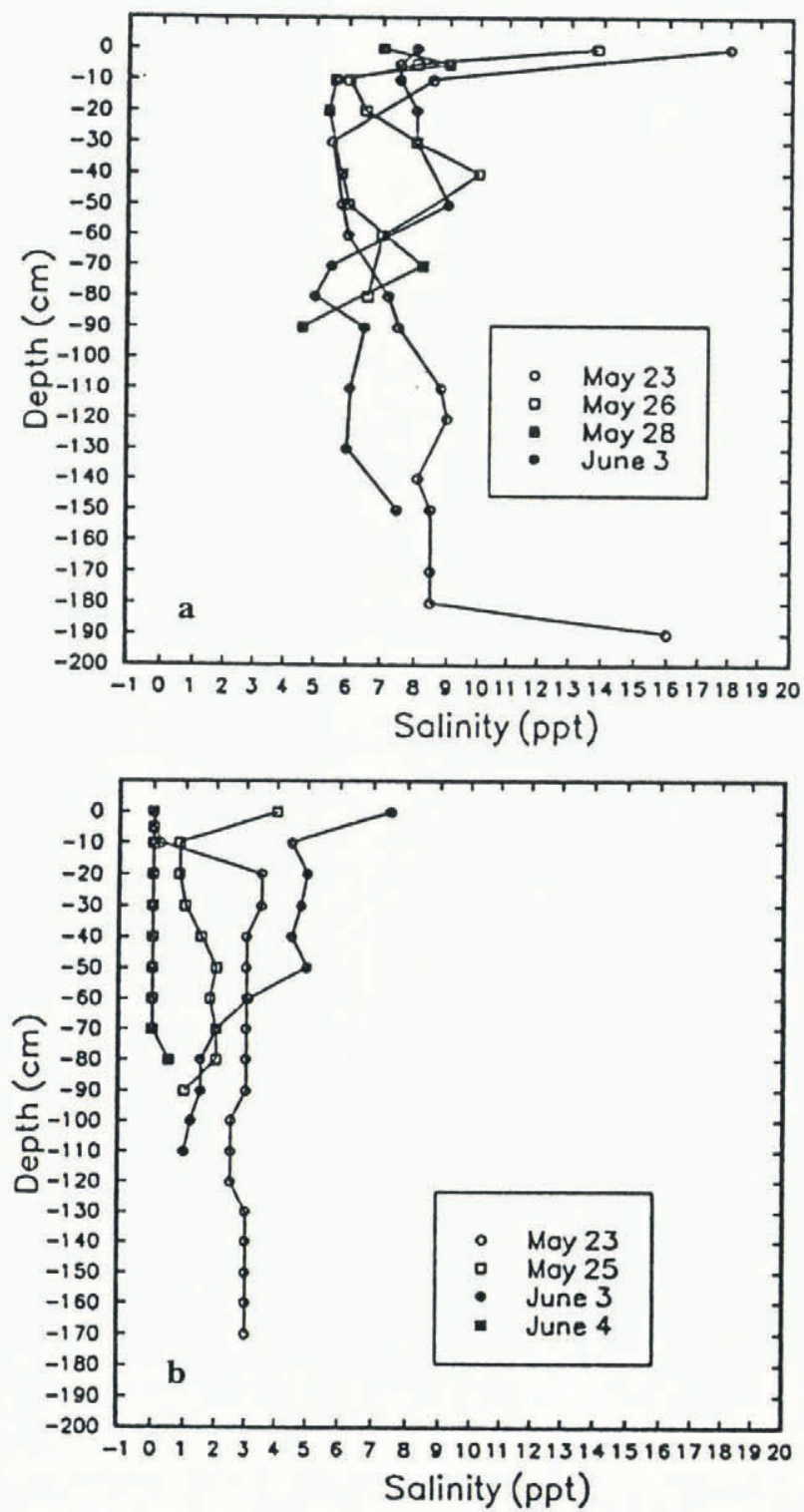

Fig. 4. Salinity profiles measured from cores of a, firstyear ice and $b$, multi-year ice. 
Profile 1 also exhibited the typical C-shape which is characteristic of winter ice. At the ice/snow interface, salinity values were found to be as high as $16 \mathrm{ppt}$, a value which is similar to the $19 \mathrm{ppt}$ obtained from the MLDBAY experiment in mid-June. Salinity measurements, however, were not conducted down to the bottom of the ice in the case of profiles 2, 3 and 4. The mean ice thickness of first-year ice in the sampling area was approximately $190 \mathrm{~cm}$. The average salinity within the sea-ice sheet was approximately $7.5 \mathrm{ppt}$ and was independent of the temporal variation of air temperature (within the measured temperature range). Salinities within the top $10 \mathrm{~cm}$ layer, however, decreased as air temperature increased. The measured salinity profiles, obtained from several first-year ice cores, spread over the sampling area, confirmed the overall homogeneity of the ice cover within that area.

Selected salinity profiles of multi-year ice are presented in Figure $4 \mathrm{~b}$. The profiles were measured from depression cores. Unlike first-year salinity profiles, no dependence on air temperature is evident. The relatively high surface salinities demonstrated in profiles 2 and 3 suggest that either a thaw hole occurred in the previous summer or flooding occurred in a depression hole. The former is a likely candidate. In a few cases of profile measurements, zero salinity was observed within the top layer of the multi-year ice. Two examples are shown in Figure 4b: profile 1 (in the top $10 \mathrm{~cm}$ ) and profile 4 (in the top $60 \mathrm{~cm}$ ). In the case of profile 1 , the zero salinity indicates the presence of a fresh-water ice layer, typical of a melt pond. In the case of profile 4 , the zero salinity is probably the result of brine drainage, since the corresponding temperature profile (Fig. 3b) shows zero temperature within the top $40 \mathrm{~cm}$ of the ice cover. Average salinities from profiles 1, 2, 3 and 4 are 2.6, 1.2, 4.6 and $0.0 \mathrm{ppt}$, respectively. These values agree reasonably well with the typical winter values of $0.1-3 \mathrm{ppt}$ as mentioned above (although profile 1 shows a higher salinity). As expected, the multi-year ice profiles are less variable than the first-year ice profiles.

In Fram Strait MIZEX'84, the bulk salinity of firstyear ice was found to be a function of ice thickness. For $2 \mathrm{~m}$ thickness, bulk salinity was approximately $4 \mathrm{ppt}$. Lower salinities of 1.0-3.0 ppt were observed near the top ice surface. This was related to the drainage, resulting from ice warming prior to sampling (which was conducted in mid-June). In the Beaufort Sea, results from the OCSEAP experiment show that the bulk salinity measured in late May is approximately $4 \mathrm{ppt}$, while the surface near-zero salinities replace the higher values measured in the winter season. A detailed study on ice salinity in Mould Bay was conducted during the MLDBAY experiment. The study showed that the average bulk salinity, obtained at five locations across the bay, on 13 June, was 4.8 ppt. Salinity values in the upper $10 \mathrm{~cm}$ ranged from 0 to $6 \mathrm{ppt}$ with an average of 4 ppt. In the Weddell Sea WWSP' 86 experiment, salinity measurements obtained between 28 November and 6 December showed that the average salinity during the onset of the melt season was $4.3 \mathrm{ppt}$. In another experiment in the Weddell Sea, conducted in February and March 1980 during the advanced melt season, Gow and others (1982) reported an average salinity of $4.6 \mathrm{ppt}$, measured from 33 first-year ice floes. A systematic approach to studying the evolution of salinity throughout the ice-growth season was conducted in the PNDINLT experiment. A stable salinity profile, in which each point represents the average salinity measured during the December-May period at a given depth, has been presented by Nakawo and Sinha (1981). The bulk salinity obtained from this profile is $6 \mathrm{ppt}$. This is the ice salinity prior to the early melt season. It can be concluded from the above discussion that the average bulk salinity of $7.5 \mathrm{ppt}$, measured from 15 cores in the SIMS'90 experiment, is higher than the corresponding values in all regions considered in this comparison. The only exception is the Pond Inlet region which shows salinity values very close to those obtained from the SIMS '90 region. Pond Inlet is about $600 \mathrm{~km}$ southeast from the SIMS '90 site. Higher salinity means higher icegrowth rates. The latter is a function of temperature and wind conditions which are regionally dependent parameters.

For multi-year ice, results from the AIDJEX experiment in the Beaufort Sea showed that salinity profiles from hummocks and depressions were significantly different. Cox and Weeks (1974) concluded that salinity values beneath a depression were both higher and more variable than corresponding values beneath a hummock. Bulk salinities from depression cores were approximately $5.5 \mathrm{ppt}$. This is a slightly higher value compared to the average bulk salinity of $3.1 \mathrm{ppt}$ obtained from the SIMS'90 depression cores. Results from the MIZEX'84 experiment showed bulk salinities between 2.0 and $2.5 \mathrm{ppt}$, which are closer to the SIMS'90 results. Nonetheless, it is difficult to postulate upon a regionally dependent description of multi-year ice because of the continuous motion of ice floes in the summer, which causes the floes to settle far from their original formation region.

\subsubsection{Ice-surface roughness}

The r.m.s. values of surface roughness are shown in Figure 5. Each data point is an average of many r.m.s. estimates (between 4 and 40) at the same measuring site. Qualitative analysis of the figure shows a tendency of slight increase in r.m.s. values towards the last week in May, although the last data point, obtained from firstyear ice on 5 June, does not support this tendency. The minimum and maximum r.m.s. values were 17 and $36 \mathrm{~mm}$, respectively, and the average was about $23 \mathrm{~mm}$. This surface is considered rough with respect to the Cband $(5.3 \mathrm{~cm}$ wavelength) radar energy at operational incidence angles of SAR, according to Fraunhofer criterion (Ulaby and others, 1986). The data show no significant difference between first-year and multi-year ice-surface roughness. Onstott and Gogineni (1985) stated that in the early melt season, ice-surface roughness is modulated by the addition of melt-induced superimposed ice. They reported surface-roughness height ranges of 9.32-27.78 $\mathrm{mm}$ for first-year ice in the Mould Bay area, with corresponding r.m.s. values of 2.1 and $4.93 \mathrm{~mm}$ measured on 14 and 16 June, respectively. These values are almost an order of magnitude less than those obtained in SIMS '90. No explanation, beyond that of the regionaldifference contribution, can be offered at this point. Holt 


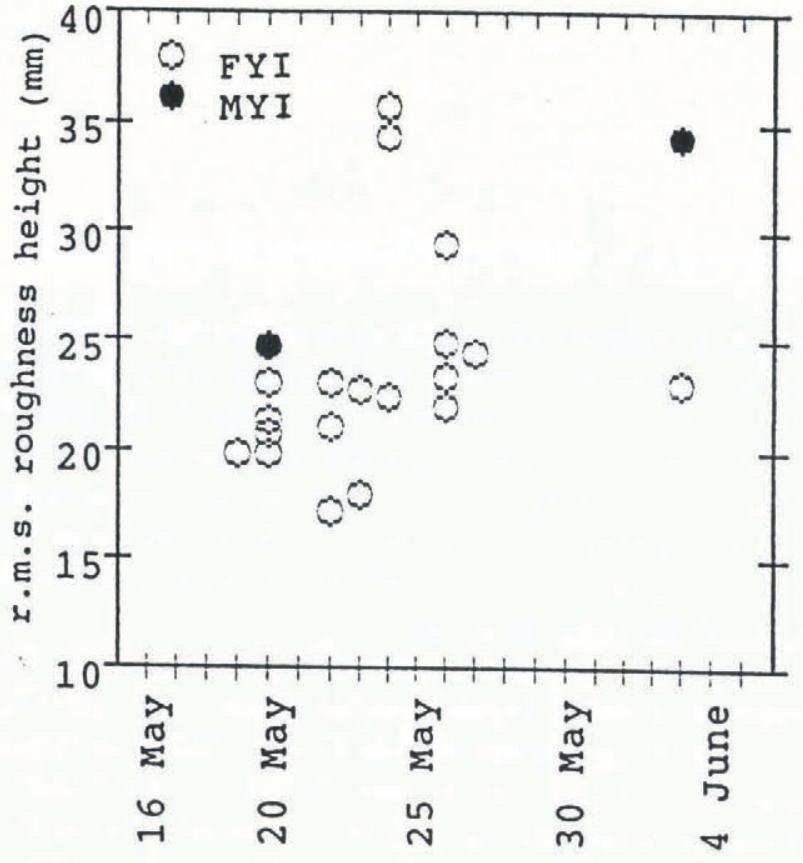

Fig. 5. r.m.s. of surface-roughness heights.

and Digby (1985) also reported that ice is roughened in the early melt season by snow nodules which are formed by the freezing of water vapour in the high-humidity snow-hoar layer around cooler snow particles and the ice crust. Data on ice-surface roughness are scarce in the literature, so that a fair comparison with the present data is not feasible.

\subsection{Measured snow properties}

\subsubsection{Snow depth}

The average snow depth obtained from the SIMS'90 experiment was 20.5 and $36.2 \mathrm{~cm}$, for first-year and multiyear ice, with a standard deviation of 4.8 and $12.5 \mathrm{~cm}$, respectively. The higher standard deviations of multi-year ice are due to the undulating topography of the ice surface. In the MIZEX'84 experiment, a more significant difference between snow depth on first-year and multiyear ice was noted. Snow depth on first-year ice averaged only $8 \mathrm{~cm}$ and never exceeded $20 \mathrm{~cm}$, while snow depth on multi-year ice averaged $40 \mathrm{~cm}$ and ranged from approximately 30 to $50 \mathrm{~cm}$, measured in the period $15-20$ June. Tucker and others (1987) related the thicker snow cover on multi-year ice to the ice thickness. They suggested that, for thinner ice types (first-year ice), more heat was conducted from the ocean to the ice surface and therefore snow would be more susceptible to loss by sublimation. In the AIDJEX experiment, snow depth on multi-year ice averaged $10 \mathrm{~cm}$ on hummocks and $30 \mathrm{~cm}$ on melt ponds. In the PNDINLT experiment, the snow depth on firstyear ice averaged $15 \mathrm{~cm}$ with a standard deviation of $4.7 \mathrm{~cm}$ during the first week in May. In the MLDBAY experiment, a similar average of $14 \mathrm{~cm}$ was recorded on 14 June, decreasing from an average of $30 \mathrm{~cm}$ recorded on 7 June. These values are similar to SIMS' 90 data.

\subsubsection{Snow-hoar layer characteristics}

At the base of the snowpack, a hoar layer was observed during SIMS'90. This layer was characterized by large needle and capped columnar-shaped crystals which are a direct result of constructive metamorphism within the basal layer of the snow cover. The strong temperature gradient which existed between the atmosphere and sea ice creates an associated vapour gradient (Langham, 1981). The columnar crystals of the hoar layer are a result of this vapour gradient. The observed salinities of the hoar layer were consistently higher than the $-2.5 \mathrm{~cm}$ layer salinities of the sea-ice surface. Although the process of salt migration into the snow cover is not well understood, it would appear that a likely candidate is capillary suction (Drinkwater and Crocker, 1989; Lohanick, 1990). Deposition of a snow layer on to a highly saline (frostflowered) first-year ice surface allowed capillary suction to draw brine into a snowpack. SIMS'90 observations indicate that salinities are highest within the hoar layer but can migrate beyond the region impacted by the vapour-gradient metamorphosis (see section 3.3).

For the first-year ice, the hoar-layer thickness, measured during the last week in May and the first week in June, had a mean value and standard deviations of 3.88 and $1.22 \mathrm{~cm}$, respectively. The corresponding values in the case of multi-year ice were 4.38 and $1.50 \mathrm{~cm}$, respectively. The average crystal diameter in the hoar layer was about $4.0 \mathrm{~mm}$, measured in the first week in June. Ice nodules of about $1-2 \mathrm{~cm}$ length were observed at the bottom of the hoar layer. It should be mentioned, however, that no change in snow depth was observed during the experiment period. More results on the snow structure can be found in Barber and others (1992). In the MLDBAY experiment, a bottom layer (approximately $4 \mathrm{~cm}$ ) of low-density snow was observed on 13 June. The snow-crystal size ranged from 1 to $5 \mathrm{~mm}$. The structure of the snow cover changed significantly from 13 to 21 June when the entire snow cover disappeared. In the WWSP'86 experiment, depth-hoar crystals up to $5 \mathrm{~mm}$ in length were found immediately above the snow/ ice interface in the early melt season (i.e. October).

\subsubsection{Effect of snow depth on the ice-surface temperature}

Ice-surface temperature is affected by the snow cover and so are the dielectric and microwave-scattering properties. The effect of snow depth on the relationship between icesurface temperature and air temperature are presented in Figure $6 \mathrm{a}$ and b for first-year and multi-year ice. Each figure includes two data sets collected under two different snow-depth ranges, as indicated in the figures. In order to study the effect of snow depth on the above-mentioned relationship, the effect of temporal variation of snow properties had to be removed. This was achieved by using data collected during a relatively short period of time, namely, from 27 May to 4 June 1990. In the case of firstyear ice (Fig. 6a), snow depth does not seem to affect the relationship between ice-surface temperature and air temperature. This is evident from the substantial overlap between the two sets of data points, measured under average snow depths of 14 and $38 \mathrm{~cm}$. In the case of multiyear ice (Fig. 6b), the snow cover seems to affect the relationship when air temperature is above $-4^{\circ} \mathrm{C}$. This can be concluded from the separability between the two sets of data points measured under average snow depths of 15 and $42.5 \mathrm{~cm}$. Under relatively thin snow cover, 12$18 \mathrm{~cm}$, the multi-year ice-surface temperature adjusted quickly to the warm air temperature. This was not the 

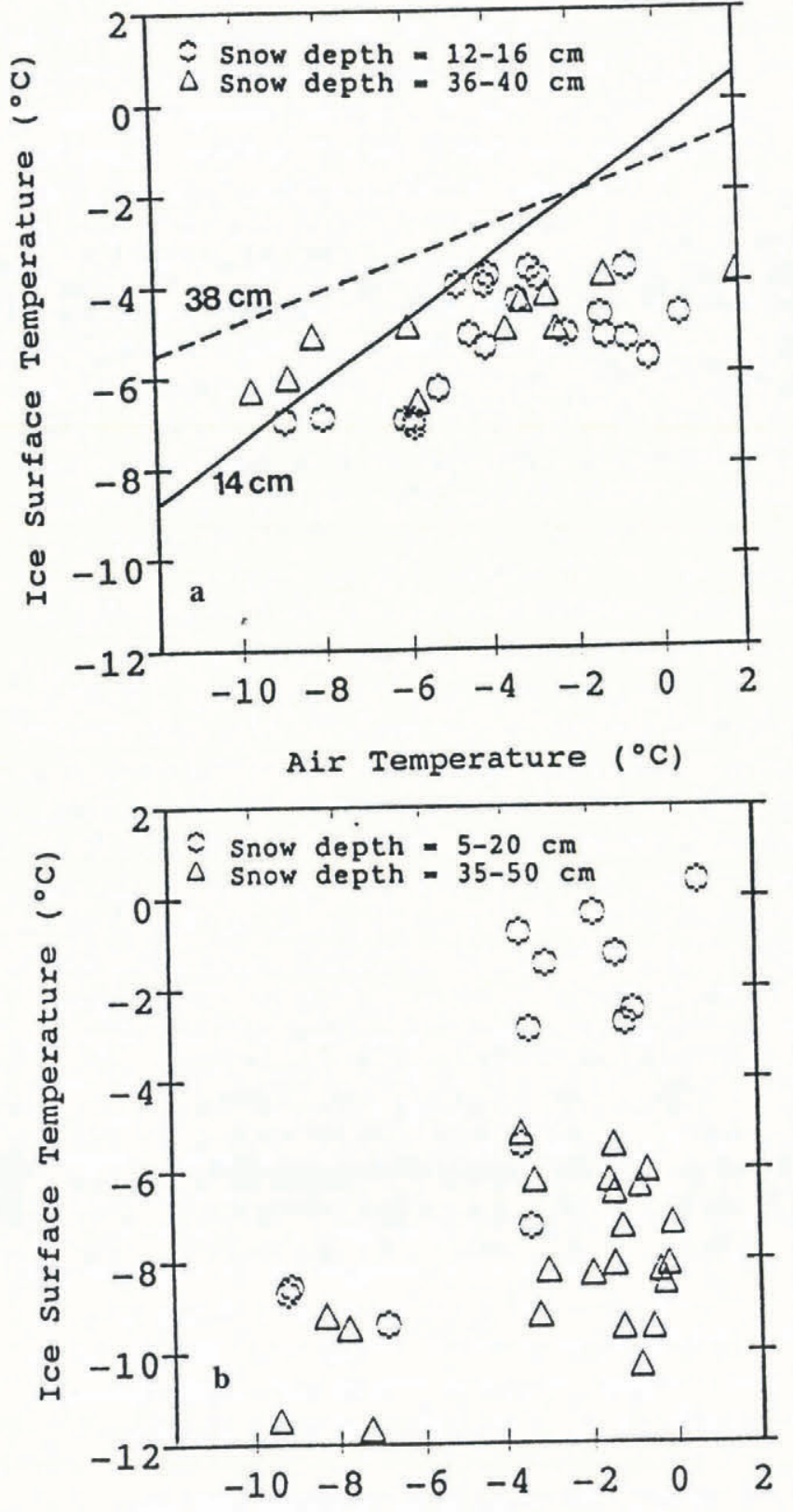

Air Temperature $\left({ }^{\circ} \mathrm{C}\right)$

Fig. 6. Effect of snow depth on the relationship between ice-surface temperature and air temperature for a, first-year ice and $b$, multi-year ice.

case, however, under a thicker snow cover, namely 35$50 \mathrm{~cm}$. Note that when the air temperature is below $-5^{\circ} \mathrm{C}$, the snow depth does not have the same effect on the icesurface temperature. The results provide evidence that the snow cover has more insulating effect on the first-year ice than on the multi-year ice surface. Further examination will be conducted in future experiments.

Results of ice-surface temperatures, using Equation (1), were obtained for first-year ice of $200 \mathrm{~cm}$ depth, and two snow depths of 14 and $38 \mathrm{~cm}$. Results are shown by the two solid curves in Figure 6a. It can be seen that, for air temperature below $-6^{\circ} \mathrm{C}$, the model overestimates the ice-surface temperature, especially at the thicker snow depth. The basic assumption implied in the model, namely, the constant temperature gradient within the ice and snow volume, is no longer valid during the early melt season even though it has been confirmed by a few measurements in this experiment (e.g. profiles 1 and 2 in Figure 3a). An appropriate model for ice-surface temperature is important for calculating the evolution of ice-dielectric properties during transition from winter to summer conditions.

\subsection{Temporal variation of measured properties}

Temporal variation of ice and snow properties, measured over the experiment period, for first-year and multi-year ice data are shown in Figures 7 and 8, respectively. Figure 7a through e show the variation of air temperature, icesurface temperature, ice-surface salinity, snow-hoar layer salinity and snow thickness, respectively. In several of the plots, a regression line is fitted to the data in order to delineate the seasonal trend.

Figure $7 \mathrm{a}$ shows a trend of atmospheric warming. Air temperature varied between approximately $-10^{\circ}$ to $0^{\circ} \mathrm{C}$, at a rate of approximately $0.335^{\circ} \mathrm{C} \mathrm{d}^{-1}$. Based on visual assessment of the figure, two cycles of temperature increase/decrease can be noticed: one during the period from 24 to 29 May and the other during the period from 29 May to 5 June. These cycles leave their signature (though not as sharp) on the ice-surface temperature variation as shown in Figure $7 \mathrm{~b}$. No other measured physical property responded to such a cyclic pattern. A distinct trend of increase in ice-surface temperature is evident in Figure $7 \mathrm{~b}$, with a relatively small deviation of data points from that trend. The ice-surface temperature rose at a gradient of approximately $0.178^{\circ} \mathrm{Cd}^{-1}$, which was almost half of the corresponding gradient of airtemperature increase. This difference can be attributed to the insulating effect of the snow cover on first-year ice as discussed in section 3.2.3.

The rapid desalination trend of the ice-surface layer (top $5 \mathrm{~cm}$ ) is depicted in Figure 7c. On 16 May, the average salinity was $12 \mathrm{ppt}$ and on 5 June it decreased to $5.2 \mathrm{ppt}$. The desalination rate was approximately $0.287 \mathrm{ppt} \mathrm{d}^{-1}$, which is considerably higher than a correpsonding rate of $0.04 \mathrm{ppt} \mathrm{d}^{-1}$, calculated from results of the MLDBAY experiment during the melt onset and the advanced melt seasons (from 13 June to 13 July). If regional differences between these two sets of data are neglected, it can be concluded that the ice cover experienced a higher desalination rate in the early melt season compared to the melt-onset season. More data, however, are required to support this conclusion. In the PNDINLT experiment, ice salinity measured at a depth of $17.5-20 \mathrm{~cm}$ dropped from $5.2 \mathrm{ppt}$ in December to $3.8 \mathrm{ppt}$ in May. This rate, of approximately $0.00875 \mathrm{ppt} \mathrm{d}^{-1}$, represents the typical winter desalination which is much slower than the rate in the early melt season. Nakawo and Sinha (1981), however, reported that desalination with increasing rapidity was observed during the May-June period.

The average salinity of the snow-hoar layer (Fig. 7d) decreased gradually during the experiment period at a rate of $0.177 \mathrm{ppt} \mathrm{d}^{-1}$, which was considerably smaller than that of ice desalination as specified above. This gave rise to higher salinities of the hoar layer compared to salinities of the ice-surface layer, especially towards the end of the early melt season. For example, in the first week of June, the hoar-layer salinity was about $12 \mathrm{ppt}$, while the ice 

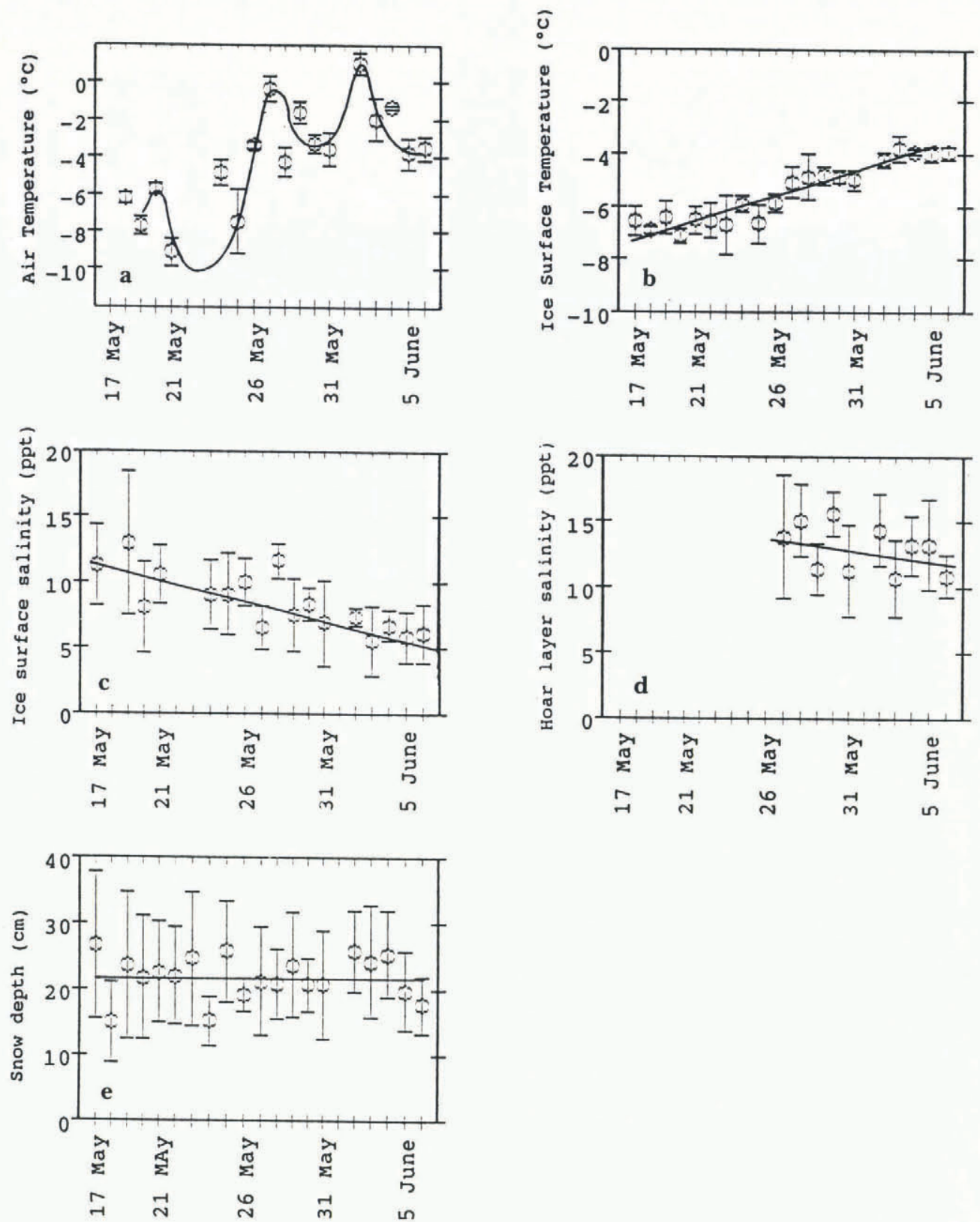

Fig. 7. Temporal variation of air, snow and ice parameters obtained from first-year ice measurements. a, air temperature; $b$, ice temperature; $c$, ice-surface salinity; $d$, hoar-layer salinity; $e$, snow depth.

salinity was only $6 \mathrm{ppt}$. In the WWSP' 86 experiment, salinities as high as $50 \mathrm{ppt}$ were measured in the hoar layer in October but the average salinity at the snow/ice interface was $15 \mathrm{ppt}$, which is comparable to the SIMS '90 measurements.

The average snow depth (Fig. 7e) was $20.5 \mathrm{~cm}$ during the experiment period, with an expectedly large scattering of data points, since snow accumulation varies widely with location. The snow density over first-year and multiyear ice was $0.319 \pm 0.065 \mathrm{Mg} \mathrm{m}^{-3}$ and $0.291 \pm$ $0.072 \mathrm{Mg} \mathrm{m}^{-3}$, respectively. This is a significant increase from the newly fallen snow density of $0.05 \mathrm{Mg} \mathrm{m}^{-3}$. Snow density did not vary during the experiment period. The measured values are in good agreement with an earlier value of $0.356 \pm 0.052 \mathrm{Mg} \mathrm{m}^{-3}$ obtained at Resolute Bay by Williams and Gold (1958). In the pack ice in the central Weddell Sea (WWSP'86 experiment), the snow metamorphosed from an average density of $0.375 \mathrm{Mg} \mathrm{m}^{-3}$ (starting at $0.3 \mathrm{Mg} \mathrm{m}^{-3}$ at the top to $0.45 \mathrm{Mg} \mathrm{m}^{-3}$ at the bottom) in October, to approximately $0.5 \mathrm{Mg} \mathrm{m}^{-3}$ in November. This was due to the wet snow conditions existing at that time.

The corresponding measurements of multi-year ice show the same cyclic pattern of air temperature (Fig. 8a) as that recorded during the first-year ice measurements. Unlike first-year ice, however, this pattern did not leave its signature on the multi-year ice-surface temperature (Fig. 8b), probably because of the thicker snow cover. The figure also revealed another dissimilarity between the two ice types; the multi-year ice surface elicited a variance in temperature which, again, increased towards the end of the experiment period. This was a result of the development of bare hummock surfaces and snowcovered melt ponds which were exposed to warm air and consequently resulted in a dramatic change in the integrated surface albedo of the multi-year ice. It can be seen from Figure $8 \mathrm{a}$ and $\mathrm{b}$ that the variance achieved its maximum value on 2 June, when the maximum air 

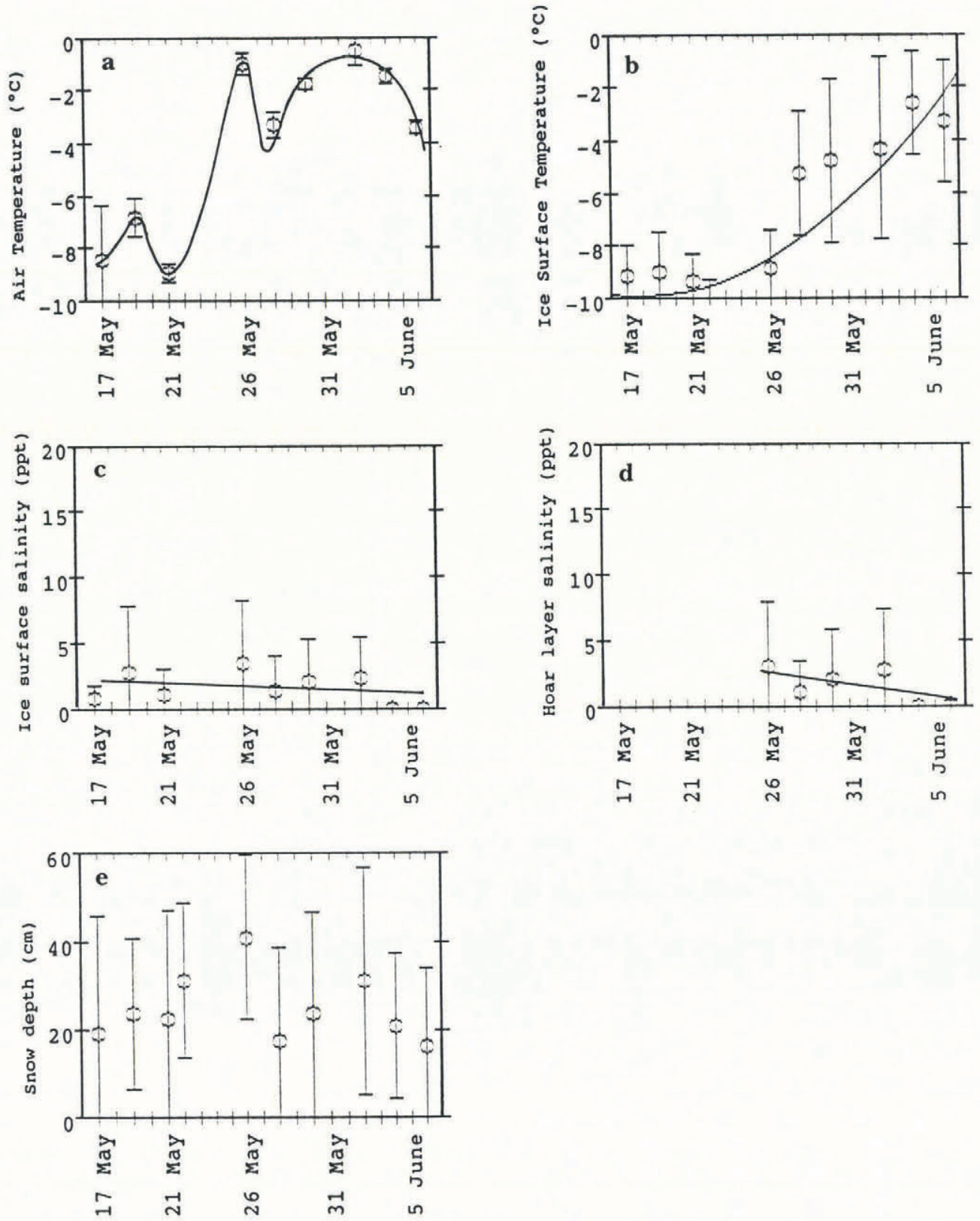

Fig. 8. Temporal variation of air, snow and ice parameters obtained from multi-year ice measurements. a, air temperature; $b$, ice temperature; $c$, ice-surface salinity; $d$, hoar-layer salinity; e, snow depth.

temperature was recorded. This was perhaps because icesurface temperatures had not been adjusted to the sudden increase in air temperature on that day.

Ice-surface salinities (Fig. 8c) were mostly below 5 ppt. The rate of desalination of the multi-year ice surface is almost negligible compared to that of first-year ice because of the almost brine-free multi-year ice surface. In the MIZEX'84 experiment, multi-year ice salinities also showed no temporal dependence during June and July. The hoar-layer salinities from SIMS '90 data (Fig. 8d) show a similar trend to that of the ice-surface salinity (i.e. salinity was reduced to near-zero values by 6 June). The desalination rate of the hoar layer, calculated from the limited number of points in Figure $8 \mathrm{~d}$, is $0.127 \mathrm{ppt} \mathrm{d}^{-1}$, which is close to the desalination rate of the hoar layer above first-year ice $\left(0.177 \mathrm{ppt}^{-1}\right)$. As in the case of the first-year ice, no temporal variation of snow thickness (Fig. 8e) was noted.

\subsection{Ice-dieletric properties}

Temporal variations of the permittivity and dielectric loss (the mean \pm one standard deviation) in the ice-surface layer are shown in Figures 9 and 10 for first-year and multi-year ice measurements, respectively. The parameters were calculated from measurements obtained at $2.5 \mathrm{~cm}$ depth below the ice surface (i.e. within the penetration depth of the two operational imaging-radar frequencies: $\mathrm{X}$ and $\mathrm{C}$ bands). In the case of first-year ice, the average values of $\epsilon^{\prime}$ and $\epsilon^{\prime \prime}$ calculated from Vant's model are 3.64 and 0.31 , respectively. The corresponding values from Hoekstra and Cappillino's model are 4.25 and 0.50 , respectively. Little temporal variation in either parameter is observed. This means that brine volume did not increase during the early melt season despite the observed desalination rate of $0.287 \mathrm{pptd}^{-1}$ (see section 3.3). The variability in $\epsilon^{\prime \prime}$ is almost four times the variability in $\epsilon^{\prime}$. This is due to the higher sensitivity of $\epsilon^{\prime \prime}$ 

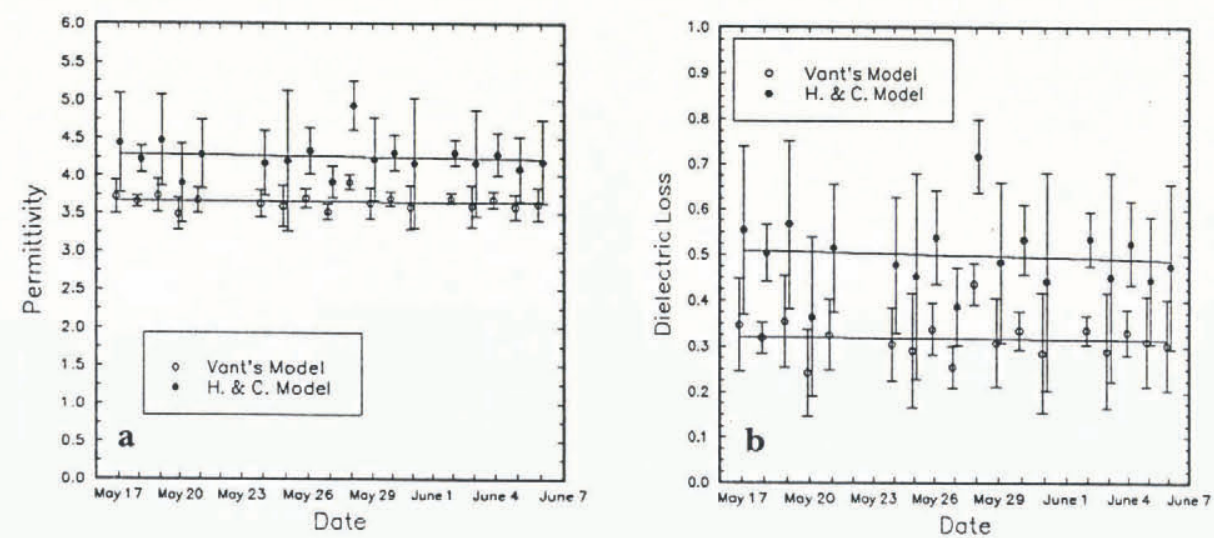

Fig. 9. Temporal variation of permittivity, a, and dielectric loss, $b$, for first-year ice, calculated for frequency $=4 \mathrm{GHz}$ using Vant's model and for frequency range $4-10 \mathrm{GHz}$ using Hoekstra and Cappillino's model.
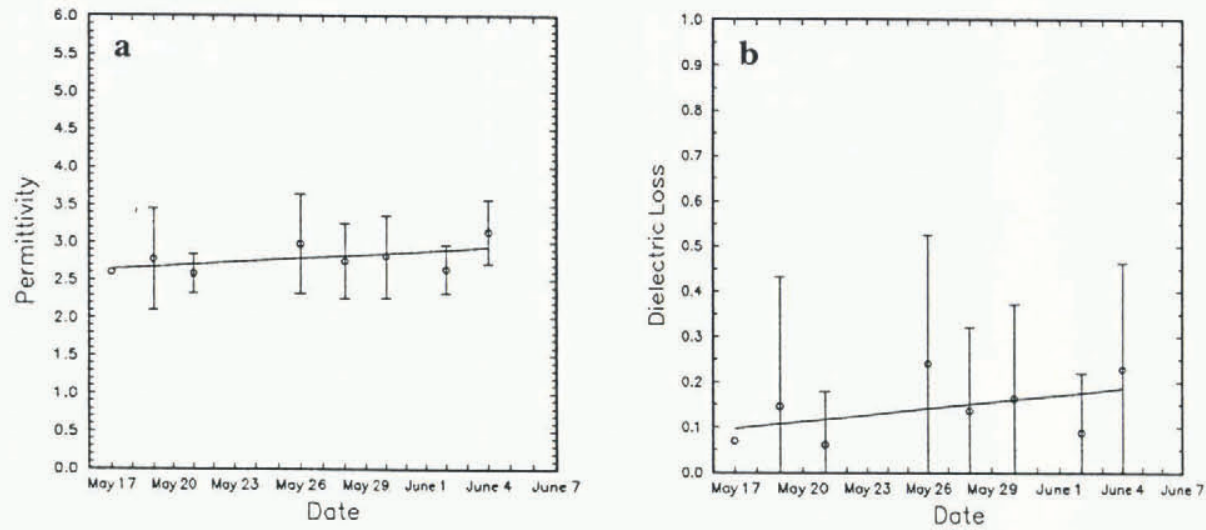

Fig. 10. Temporal variation of permittivity, $a$, and dielectric loss, $b$, for multi-year ice, calculated for frequency $=$ $10 \mathrm{GHz}$ using Vant's model.

to temperature variation. In the case of multi-year ice, a slight increase in both permittivity and loss is observed as shown in Figure 10a and b, respectively. The significance of this trend is questionable because of the large variability in the data. The variability is caused by differences in dielectric properties between hummock and depression surfaces (the figure combines data from both types). Depression cores also vary substantially in terms of shape and distribution of brine contents (Shokr and Sinha, 1992), which give rise to large variability in the dielectric constant.

Depth profiles of the permittivity and loss for first-year and multi-year ice are shown in Figures 11 and 12, respectively. The profiles were calculated using Vant's model. Two profiles marking the end of the winter conditions (profile 1 collected on 23 May) and the progress of the early melt conditions (profile 2 collected on 3 June) are shown in each figure. The first-year ice profiles 1 and 2 have an average permittivity of $3.69 \pm 0.29$ and $3.81 \pm 0.17$, respectively (Fig. 11a), and an average dielectric loss of $0.32 \pm 0.13$ and $0.369 \pm 0.08$, respectively (Fig. 11b). These values are within the expected range under winter conditions. The surface values from the two profiles are identical. This means that the effect of ice salinity, which decreased from 18 to $8 \mathrm{ppt}$, was offset by the effect of ice temperature, which increased from $-7.5^{\circ}$ to $-2.5^{\circ} \mathrm{C}$ (see Figs $3 \mathrm{a}$ and 4a). Within a depth range of $10-60 \mathrm{~cm}$, however, both permittivity and loss from profile 2 are significantly higher than those from profile 1 . This can be attributed to the higher brine volume which resulted from the higher temperatures within that depth range (see profile 4 in Figure 3a).

For multi-year ice (Fig. 12), profile 1 showed average values of 3.0 and 0.29 for $\epsilon^{\prime}$ and $\epsilon^{\prime \prime}$, respectively. These values are within the expected range for winter multi-year ice. It should be noted that the extremely small values in the upper $20 \mathrm{~cm}$ layer are due to the zero surface salinity in that layer (see Fig. 4a). Profile 2 shows significantly high values of $\epsilon^{\prime}$ and $\epsilon^{\prime \prime}$ (4.0 and 0.8 , respectively) in the upper $50 \mathrm{~cm}$ layer. These values are much higher than the expected average complex dielectric constant of multiyear ice $(\sim 3.15-0.1)$. Assuming the validity of Vant's model, the results confirm the general observation that the formation of first-year ice on top of a multi-year floe can physically alter the dielectric properties of this volume. It should be mentioned that profile 2 is not representative of the dielectric constant values obtained during the experiment period.

The temporal variation of microwave-penetration depth in ice was obtained from the dielectric constant. The values were calculated from ice measurements at $2.5 \mathrm{~cm}$ depth. The variation is shown in Figure 13. No trend was observed in the first-year ice data. The mean and the standard deviation from Vant's model are 12.03 and $3.58 \mathrm{~cm}$, and from using Hoekstra and Cappillino's 

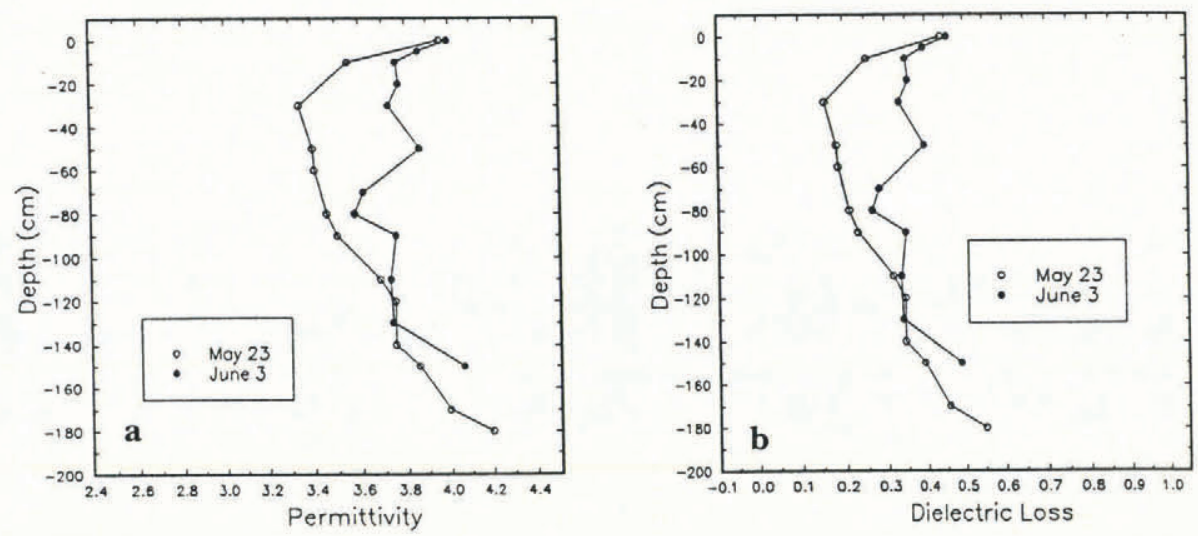

Fig. 11. Depth profiles of permittivity, $a$, and dielectric loss, $b$, for first-year ice, calculated for frequency $=10 \mathrm{GHz}$ using Vant's model.
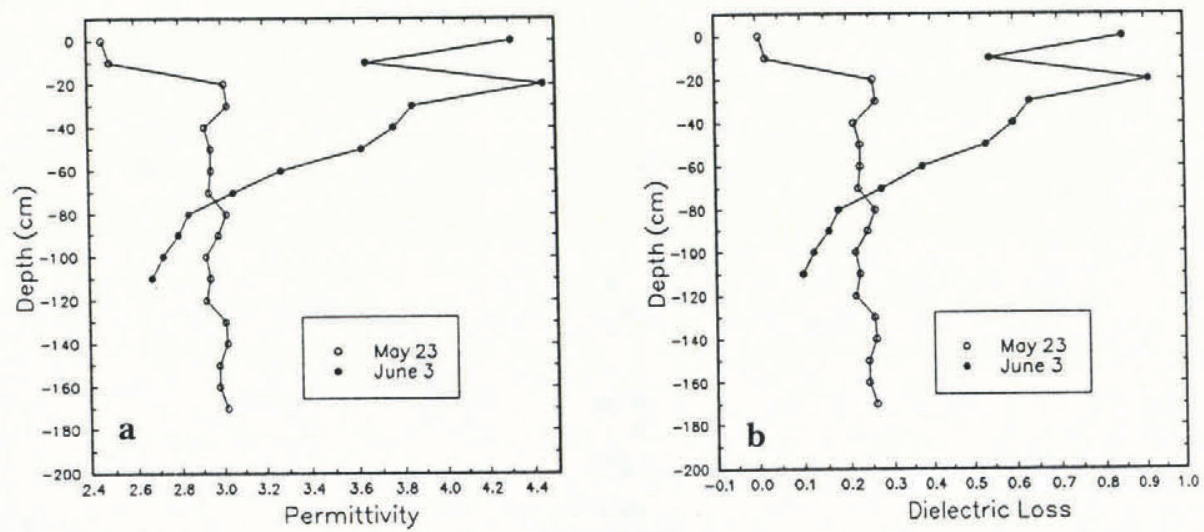

Fig. 12. Depth profiles of permittivity, $a$, and dielectric loss, $b$, for multi-year ice, calculated for frequency $=10 \mathrm{GHz}$ using Vant's model.

model are 3.16 and $1.05 \mathrm{~cm}$. A drop in the penetration depth, from about $9 \mathrm{~cm}$ on 17 May to about $4 \mathrm{~cm}$ on 4 June is observed in the multi-year ice data. This can be attributed to the increase in brine-volume content in saline-depression cores as temperatures rose. The quick

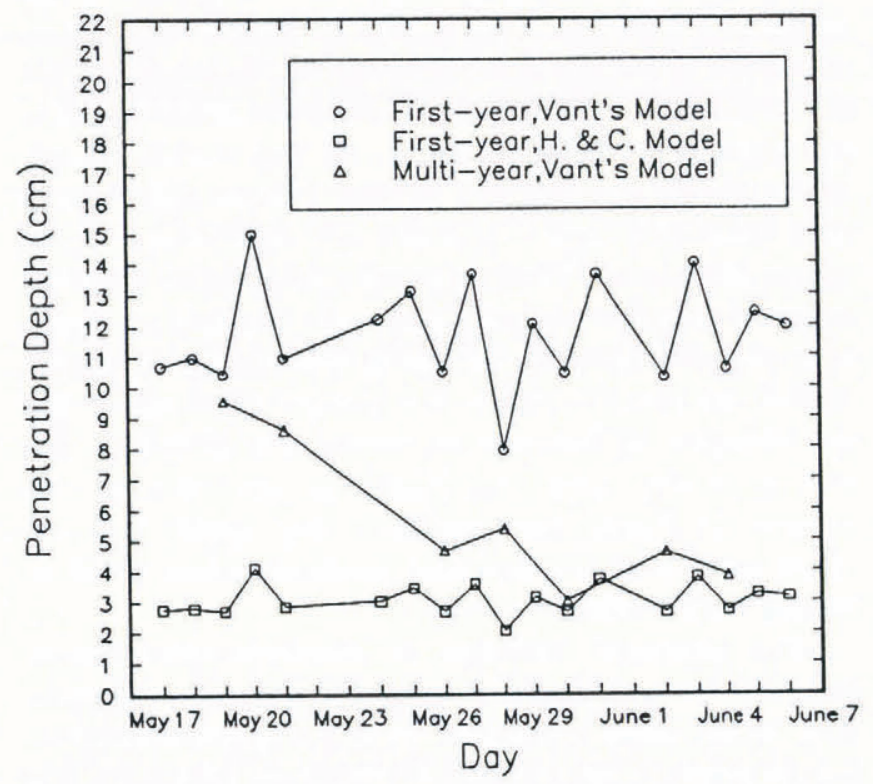

Fig. 13. Temporal variation of penetration depth for firstyear and multi-year ice using Vant's model and Hoekstra and Cappillino's model. adjustment of the multi-year ice surface to the air temperature (see section 3.2.3) supports this explanation.

\section{CONGLUSIONS}

The first field experiment in the seasonal Sea Ice Monitoring Site program was conducted in Resolute Passage, Northwest Territories, during the period 15 May-8 June 1990. A primary objective was to characterize the temporal variation of ice and snow properties during the early melt season. This information can be used in developing a better understanding of and capability to extract information from microwave remote-sensing of ice. In this paper, we report on experimental findings and also on a limited comparison of results with other studies conducted in geographic regions of similar climatological conditions. The main conclusions from the present study are highlighted in the following:

1. Temperature profiles are characterized by a zero or negative gradient in the ice-surface layer followed by a linear increase towards the ice bottom. This pattern is evoked at an air temperature of about $-5^{\circ} \mathrm{C}$, and it seems to be regionally independent.

2. Relatively higher salinities of first-year ice are apparently unique to this geographic area. The bulk salinity of first-year ice was 7.5 ppt. Bulk salinities 
from depression cores of multi-year ice were about $3.1 \mathrm{ppt}$.

3. The average r.m.s. value of ice-surface roughness was almost constant, $23 \mathrm{~mm}$, over the experiment period. This is an order-of-magnitude higher than roughness measurements obtained in the Beaufort Sea (Onstott and Gogineni, 1985).

4. The average snow depth was 20.5 and $36.2 \mathrm{~cm}$ on first-year and multi-year ice, respectively. These results agree with previous experimental data obtained in the other geographic regions addressed in this paper. The only exception is the MIZEX' 84 data where a significant difference between snow accumulation on first-year and multi-year ice was reported.

5. Seasonal warming was observed during the experiment period, with two cycles of air-temperature increase/decrease. Those cycles were replicated by icesurface temperature. The ice-surface temperature increased by an average gradient of $0.178^{\circ} \mathrm{Cd}^{-1}$, which was almost half of the corresponding gradient of air-temperature rise.

6. A rapid desalination, at a rate of approximately $0.287 \mathrm{ppt} \mathrm{d}^{-1}$, was observed at the surface layer. This is higher than a rate of $0.04 \mathrm{ppt} \mathrm{d}^{-1}$ calculated from the MLDBAY experiment during the melt onset season. A slower rate of desalination, $0.177 \mathrm{ppt} \mathrm{d}^{-1}$, of the snowhoar layer on first-year ice was also observed. This gave rise to higher salinities of the snow-hoar layer towards the end of the early melt season.

7. No variation in the permittivity and dielectric loss of first-year ice was observed during the progress of the early melt season. Consequently, the penetration depth for microwave radiation was maintained at a constant value $(12.03 \mathrm{~cm}$ from using Vant's model for a frequency of $4 \mathrm{GHz}$, and $3.58 \mathrm{~cm}$ from using Hoekstra and Cappillino's model for a frequency range between 4 and $10 \mathrm{GHz}$ ). A slight increase in the dielectric constant was observed in the case of multiyear ice. This caused the penetration depth to drop from 3.16 to $1.05 \mathrm{~cm}$ (from using Vant's model for a frequency of $10 \mathrm{GHz}$ ).

More rigorous regional and inter-regional comparisons are required in order to confirm (or deny) the interrelationships identified here. Our objective has been to summarize the range and magnitude of snow and sea-ice geophysical properties over the early part of the transitional period from the winter to summer. Our observations indicate that regional differences do exist but these are primarily a function of regional atmospheric or hydrospheric forcings. Further studies are required to evaluate the utility of microwave remote-sensing of sea ice as a tool in monitoring the seasonal evolution of the seaice volume. We require an answer to: "can we detect the difference between variability and change?"

\section{ACKNOWLEDGEMENTS}

Funding for the SIMS '90 experiment was provided by the following agencies: Institute for Space and Terrestrial Science (ISTS), Aerospace Meteorology Division of the Atmospheric Environment Service (AES), Ice Centre Environment Canada (ICEC), Canada Centre for Remote Sensing (CCRS) and NSERC. The authors wish to acknowledge the effort of the SIMS '90 field crew: R. DeAbreu, D. Flett, D. Johnson, S. Paterson, C. Garrity, D. Wells, D. Hagen and J. Parent. The contribution of $\mathrm{Mr} \mathrm{J}$. Orchard of University of Waterloo in preparing the graphs is also appreciated.

\section{REFERENCES}

Barber, D. G. 1990. Science issues of a seasonally varying snow covered sea ice surface: the SIMS SAR surface validation experiment. Waterloo, Ontario, University of Waterloo. Earth Observations Laboratory. (Technical Report ISTS-EOL-SIMS-TR90-003.)

Barber, D. G., D. D. Johnson and E.F. LeDrew. 1991. Measuring climatic state variables from SAR images of sea ice: the SIMS SAR validation site in Lancaster Sound. Arctic, 44, Supplement 1, 108121.

Barber, D. G., D. G. Flett, R. DeAbreu and E. F. LeDrew. 1992. Spatial and temporal variation in sea ice geophysical properties and microwave remote sensing data: the SIMS'90 experiment. Arctic, 45(3), 233-251.

Carslaw, H. S. and H. C. Jaeger. 1959. Conduction of heat in solids. Oxford, Clarendon Press.

Colbeck, S. C. 1982. An overview of seasonal snow metamorphism. Rev. Geophys. Space Phys., 20(1), 45-61.

Cox, G.F.N. and W.F. Weeks. 1974. Salinity variations in sea ice. 7 . Glaciol., 13(67), 109-120.

Cumming, W. 1952. The dielectric properties of ice and snow at $3.2 \mathrm{~cm}$. 7. Appl. Phys., 23(7), 768-773.

Drinkwater, M. R. and G. B. Crocker. 1988. Modelling changes in the dielectric and scattering properties of young snow-covered sea ice at $\mathrm{GHz}$ frequencies. F. Glaciol., 34(118), 274-282.

Eicken, H. and M. A. Lange. 1989. Development and properties of sea ice in the coastal regime of the southeastern Weddell Sea. J. Geophys. Res., 94(C6), 8193-8206.

Evans, S. 1965. Dielectric properties of ice and snow-a review. $\mathcal{J}$. Glaciol., 5(42), 773-792.

Flett, D. G., R. A. DeAbreu, D. G. Barber and E. F. LeDrew, eds. 1990. SIMS'90 data report. Waterloo, Ontario, University of Waterloo. Earth Observations Laboratory. (Technical Report ISTS-EOLSIMS-TR90-002.)

Frankenstein, G. and R. Garner. 1967. Equations for determining the brine volume of sea ice from $-0.5^{\circ}$ to $-22.9^{\circ} \mathrm{C}$. F. Glaciol., $6(48), 943$ 944.

Garrity, C. 1990. Snow pack properties. In Flett, D. G., R. A. DeAbreu, D. G. Barber and E. F. LeDrew, eds. SIMS'90 data report. Waterloo, Ontario, University of Waterloo. Earth Observations Laboratory, Section 5.2. (Technical Report ISTS-EOL-SIMS-TR90-002.)

Garrity, C. and B. Burns. 1988. Electrical and physical properties of snow in support of BEPERS-88. North York, Ontario, York University. (Technical Report MWG 88-11.)

Hoekstra, P. and P. Cappillino. 1971. Dielectric properties of sea ice and sodium chloride ice at UHF and microwave frequencies. 7. Geophys. Res., 76(20), 4922-4931.

Hoekstra, P. and D. Spanogle. 1972. Radar cross-section measurements of snow and ice. CRREL Tech. Rep. 235.

Holt, B. and S. A. Digby. 1985. Processes and imagery of first-year fast sea ice during the melt season. 7. Geophys. Res., 90(C3), 5045-5062.

Langham, E. 1981. The handbook of snow. Geneva, World Meteorological Organization.

Livingstone, C. E., R. G. Onstott, L. D. Arsenault, A. L. Grey and K. P. Singh. 1987a. Microwave sea-ice signatures near the onset of melt. IEEE Trans. Geosci. Remote Sensing, GE-25(2), 174-187.

Livingstone, G.E., N.P. Singh and A. L. Grey. 1987b. Seasonal and regional variations of active/passive microwave signatures of sea ice. IEEE Trans. Geosci. Remote Sensing, GE-25(2), 159-173. 
Lohanick, A.W. 1990. Some observations of established snow on saline ice and their relevance to microwave remote sensing. CRREL Monogr. 90-1, 61-67.

Loor, G.P. de. 1968. Dielectric properties of heterogeneous mixtures containing water. F. Microwave Power, 3, 67-73.

Martin, S. 1979. A field study of brine drainage and oil entrainment in first-year sea ice. F. Glaciol., 22(88), 473-502.

Mellor, M. 1977. Engineering properties of snow. F. Glaciol., 19(81), 1566.

Miller, D. H. 1981. Energy at the surface of the Earth: an introduction to the energetics of ecosystems. New York, Academic Press.

Nakawo, M. and N. K. Sinha. 1981. Growth rate and salinity profile of first-year sea ice in the High Arctic. J. Glaciol., 27(96), 315-330.

Onstott, R.G. and S.P. Gogineni. 1985. Active microwave measurements of Arctic sea ice under summer conditions. F. Geophys. Res., 90(C3), 5035-5044.

Paterson, S. 1990. Micro-scale surface roughness. In Flett, D. G., R. A. DeAbreu, D. G. Barber and E.F. LeDrew, eds. SIMS'90 data report. Waterloo, Ontario, University of Waterloo. Earth Observations Laboratory, Section 5.4. (Technical Report ISTS-EOL-SIMSTR90-002.)

Schwerdtfeger, P. 1963. The thermal properties of sea ice. F. Glaciol., 4(36), 789-807.

Shokr, M.E. and N.K. Sinha. 1992. Sea ice microstructural characteristics relevant to microwave scattering. In Ayorinde, O. A., N. K. Sinha, D. S. Sodhi and W. A. Nixon, eds. Proceedings of the 11th International Conference on Offshore Mechanics and Arctic Engineering - 1992-presented ... Calgary, Alberta, Canada, June 7-12, 1992. Vol. 4. Arctic|polar technology. New York, American Society of Mechanical Engineers, 319-327.

Stogryn, A. 1971. Equations for calculating the dielectric constant of saline water. IEEE Trans. Microwave Theory Tech., MTT-19, 733-736.

Tucker, W.B., III, A.J. Gow and W.F. Weeks. 1987. Physical properties of summer sea ice in the Fram Strait. F. Geophys. Res., 92(C7), 6787-6803.

Ulaby, F.T., R. K. Moore and A.K. Fung. 1986. Microwave remote sensing: active and passive. Vol. III. Reading, MA, Addison-Wesley Publishing Company.

Vant, M.R., R.O. Ramseier and V. Makios. 1978. The complexdielectric constant of sea ice at frequencies in the range 0.1 to $40 \mathrm{GHz}$. F. Appl. Phys., 49(3), 1264-1280.

Weeks, W. F. 1981. Sea ice: the potential of remote sensing. Oceanus, 24, $39-48$.

Weeks, W.F. and S.F. Ackley. 1982. The growth, structure and properties of sea ice. CRREL Monogr. 82-1.

Williams, G. P. and L. W. Gold. 1958. Snow density and climate. Trans. Eng. Inst. Can., 2(2), 91-94.

The accuracy of references in the text and in this list is the responsibility of the authors, to whom queries should be addressed.

MS received 9 July 1991 and in revised form 21 July 1992 